vascular biology. It is apparent that two key variables were crucial in focusing attention on the work: (1) easy availability of a source tissue (umbilical vein) to isolate and grow a relatively pure population of cells; and (2) identification of an easily demonstrable immunohistochemical and functional marker (vWF) to unequivocally identify the cells in question. Thus the biomedical community was able to appreciate and characterize a heretofore unrecognized and inaccessible endothelial organ, of great importance in human health and disease. Looking back at these successful experiments is gratifying, but looking ahead at the potential human therapeutic possibilities based on these discoveries is even more exciting.

Address correspondence to: Ralph L. Nachman, Department of Medicine, Weill Medical College of Cornell University, 1300 York Avenue, New York, New York 10021, USA. Phone: (212) 746-4720; Fax: (212) 746-8793; E-mail: rlnachm@mail.med.cornell.edu.

1. Florey, Lord. 1966. The endothelial cell. Br. Med. J. 2:487-490.

2. Kaiser, L., and Sparks, H.V. 1987. Endothelial cells. Not just a cellophane wrapper. Arch. Intern. Med. 147:569-573

3. Jaffe, E.A., Nachman, R.L., Becker, C.G., and Minick, C.R. 1973. Culture of human endothelial cells derived from umbilical veins: identification by morphologic and immunologic criteria. J. Clin. Invest. 52:2745-2756.

4. Jaffe, E.A., Hoyer, L.W., and Nachman, R.L. 1973.
Synthesis of antihemophilic factor antigen by cultured human endothelial cells. J. Clin. Invest. 52:2757-2764

5. Davie, E.W., and Ratnoff, O.D. 1964. Waterfall sequence for intrinsic blood clotting. Science. 145:1310-1312.

6. Macfarlane, R.G. 1964. Haematology: An enzyme cascade in the blood clotting mechanism and its function as a biologic amplifier. Nature. 20:498-499.

7. Lewis, W.H. 1922. Endothelium in tissue cultures. Am. J. Anat. 30:39-60.

8. Lazzarini, A.A. 1959. The effects of lipoid emulsions on arterial intimal cells in tissue culture in relation to atherosclerosis. Ph.D. thesis. Cornell University Medical College. New York, New York, USA.

9. Törö, E. 1937. Untersuchungen über die potenz endothelzellen bei der gefäss bildung en der gewebekultur. Archiv für Experimentelle Zellforschung besonders Gewbezüchtung. 20:156-171.

10. Ingenito, E.F. 1958. Cells of human heart and aorta grown in tissue culture. AMA Arch. Pathol. 65:355-359.

11. Maruyama, Y. 1963. The human endothelial cell tissue culture. Z. Zellforsch. Mikrosk. Anat. 60:69-79.

12. Fryer, O.G., Birnbaum, G., and Luttrell, C.N. 1966. Human endothelium in cell culture. J. Atheroscler. Res. 6:151-163.

13. Pomerat, C.M., and Slick, W.C. 1963. Isolation and growth of endothelial cells in tissue culture. Nature. 198:859-861.

14. Hoyer, L.W., de los Santos, R.P., and Hoyer, J.R. 1973. Antihemophilic factor antigen. Localization in endothelial cells by immunofluorescence microscopy. J. Clin. Invest. 52:2737-2744.

15. Gimbrone, M.A., Cotran, R.S., and Folkman, J. 1974. Human vascular endothelial cells in culture. Growth and DNA synthesis. J. Cell Biol. 60:673-684.

16. Jaffe, E.A., Hoyer, L.W., and Nachman, R.L. 1974. Synthesis of von Willebrand factor by cultured human endothelial cells. Proc. Natl. Acad. Sci. U. S. A. 71:1906-1909.

17. Stern, D.M., et al. 1991. Endothelium and regulation of coagulation. Diabetes Care. 14:160-166.
18. Stern, D.M., Kaiser, E., and Nawroth, P. 1988. Regulation of the coagulation system by vascular endothelial cells. Hemostasis. 18:202-214.

19. Bernard, G., et al. 2001. Efficacy and safety of recombinant human activated protein $\mathrm{C}$ for severe sepsis. N. Engl. J. Med. 344:699-709.

20. Schnitzer, J.E. 1998. Vascular targeting as a strategy for cancer. N. Engl. J. Med. 339:472-474.

21. Gimbrone, M.A., et al. 1997. Hemodynamics, endothelial gene expression and atherogenesis. Ann. N. Y. Acad. Sci. 811:1-10.

22. Gimbrone, M.A., et al. 1999. The critical role of mechanical forces in blood vessel development physiology and pathology. J. Vasc. Surg. 29:1104-1151.

23. Aird, W.C. 2003. Endothelial cell heterogeneity. Crit. Care Med. 31:5221-5230.

24. Chi, J.T., et al. 2003. Endothelial cell diversity revealed by global expression profiling. Proc. Natl. Acad. Sci. U. S. A. 100:10623-10628.

25. Nachman, R.L. 2001. Hypercoagulable states: challenges and opportunities. Trans. Am. Clin. Climatol. Assoc. 112:161-179.

26. Valla, D., et al. 1985. Primary myeloproliferative disorder and hepatic vein thrombosis. Ann. Intern. Med. 103:329-334.

27. Oh, P., et al. 2004. Subtractive proteomic mapping of the endothelial surface in lung and solid tumors for tissue specific therapy. Nature. 429:629-635.

28. Kudelka, A.P., Verschaegen, C.F., and Loyer, E. 1998. Complete regression of metastatic cervical cancer with the angiogenesis inhibitor TNP -470 . N. Engl. J. Med. 338:991-992.

29. Yang, J.C., et al. 2003. A randomized trial of bevacizumab; an anti vascular endothelial growth factor antibody for metastatic renal cancer. N. Engl. J. Med. 349:427-434.

30. Rafii, S., and Lyden, D. 2003. Therapeutic stem and progenitor cell transplantation for organ vascularization and regeneration. Nat. Med. 9:702-712

31. Shen, Q., et al. 2004. Endothelial cells stimulate self-renewal and expand neurogenesis of neural stem cells. Science. 304:1338-1340.

\title{
One thing leads to another
}

\author{
Jules Hirsch \\ Laboratory of Human Behavior \& Metabolism, Rockefeller University, New York, New York, USA.
}

\begin{abstract}
In 1956, the JCI published an article by Vincent Dole on a method for titrating plasma fatty acids that uncovered the importance of fatty acids as a substrate for glucose metabolism. When asked to prepare a historical perspective on this very popular paper, I paid Dole a visit and we reminisced. His answer to my question of how he came to do this work on plasma fatty acids was: "Well, one thing leads to another." Let me remind the reader of what "things" were like in 1956 and how they might have related to Dole's important contribution.
\end{abstract}

In 1954, when I began research in lipid chemistry and metabolism, overall biochemical understanding was being greatly energized

Nonstandard abbreviations used: NEFA, non-esterified fatty acid.

Conflict of interest: The author has declared that no conflict of interest exists.

Citation for this article: J. Clin. Invest. 114:1040-1043 (2004). doi:10.1172/JCI200422993. and expanded by the availability of isotopically labeled compounds and new analytic techniques, but lipid research was developing more slowly. It was appreciated that fats were the largest source of stored energy in the body and were also the major constituents of membranes, yet the then-current, 900-page biochemistry text of Fruton and Simmonds devoted only 25 pages to fats, phospholipids, and fatty acids (1). The real excitement was elsewhere, in learning about the structure and conformation of proteins and coming to grips with the molecular mechanisms of enzymatic control in living systems. In intermediary metabolism, the central players were the carbohydrates; updates of the latest findings could be found in large, colorful metabolic maps on doors or walls in the cramped office space of academic researchers.

Lipid research lagged because the separation of the various chemical classes of lipids required for many experiments was extremely tedious, and the characterization of molecular structures within each class was time consuming and often not reproducible. Even the name was uncertain - some investigators called them "lipids," and others, "lipides." JAMA and Lancet insisted that "lipids" 


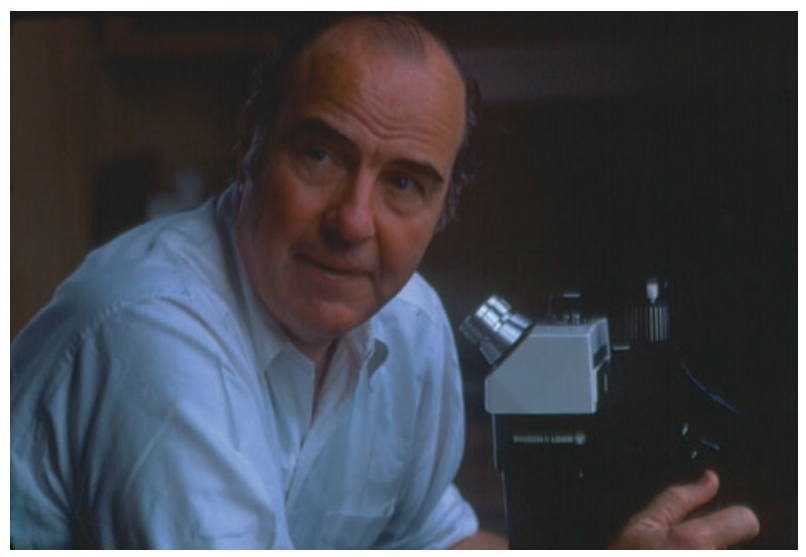

Figure 1

Vincent Dole at the bench in the 1970s.

was correct, but the august Journal of Biological Chemistry as well as the JCI insisted it was "lipides." When the field finally took off, a new arbiter, the Journal of Lipid Research was founded, and its editors ended the fracas; if you referred to them as "lipides" at this time, it would be considered an unusual affectation. With the availability of new methods, the lipid classes became separable, and gasliquid chromatography revolutionized the analysis of fatty acid mixtures. Chemical analysis of samples from blood, subjected to electrophoresis or ultracentrifugation, became a popular research endeavor, and the pressure was on to widen the scope of lipid research, particularly to determine whether dietary fat and cholesterol played some role in the mounting prevalence of arteriosclerosis and cardiovascular disease.

That was the state of affairs when I began work at the Rockefeller Institute for Medical Research with E.H. "Pete" Ahrens. Pete and I were on the 3 rd floor of the oldest building at Rockefeller, now appropriately called Founders Hall. I often saw the head of our laboratory, Vincent Dole, on the 4th floor hunched over a bench working with some glassware unfamiliar to me and partly hidden from view by a square of white paper reflecting a bright fluorescent light (Figure 1). He seemed enormously preoccupied, gazing at a bubbling solution. In those days it was not unusual to have heads of laboratories work side by side with their trainees. Close to my lab, Henry Kunkel could be seen among his fellows, laying the groundwork for modern clinical immunology, with a kitchen apron tucked into his belt and rolled-up shirtsleeves, looking like some extremely intelligent and very intense pastry chef working among his culinary acolytes.
I had no idea what Vince was doing, but he was not secretive, and I soon learned that he was using a syringe-like accurate delivery system known as a Rehberg burette to determine how much "free" fatty acid there might be in extracts of plasma lipids. All plasma lipids were suspect for a role in arteriosclerosis. I knew of the great interest in what was called "clearing factor"; injections of heparin hastened the clearing of the chylomicrons, which make plasma turbid after the ingestion of fatty meals. This was shown to be the result of activation and mobilization of a specific lipoprotein lipase. With evidence for brisk lipolytic activity in plasma, it was no surprise that there might be small amounts of free fatty acids. The lipid research community showed little interest in free fatty acids, but they were a major preoccupation for Vince Dole. Some months before beginning my research at Rockefeller, he interviewed me and impressed me enormously by explaining why it was such a great privilege to work there. Here, he noted, one was paid for learning new things with only one obligation: to keep learning something new each day. And so, unaffected by prevailing opinions, he believed that titrating plasma fatty acids might teach him something new. He did indeed learn something new and thereby wrote a new chapter in the expanding book of knowledge on lipids.

There had been a few earlier reports on the analysis of fatty acids in plasma, dating back to work of Szent-Gyorgi and Tominaga in 1924. A detailed historical account can be found in a review prepared by Fredrickson and Gordon in 1958 (2). Available methods tended to be unwieldy and imprecise, using either steam distillation or repeated extrac- tions with ether to prepare samples for titration, but the data were approximately correct, about $1 \mathrm{mEQ}$ of fatty acid per liter of plasma. Dole published his method for measuring plasma fatty acids in 1956 (3), but his work had been accepted for publication much earlier. He told me that he asked the editor to delay publication for a most unusual reason. Bob Gordon of the NIH called to apprise him of similar work under way in his laboratory, and Vince thought it would be polite to Gordon and helpful to readers to delay publication so that his work and Gordon's could appear in the same issue of the JCI in February $1956(3,4)$. Apparently there were no patents pending, no drug company support requiring approval for publication; none of the authors were members, presidents, consultants, or stock holders of biotech companies, and thus it was possible to behave in a collegial and academic way. When at last published, it became one of the most cited articles in the JCI's history: 4,292 times (as of this writing); it is worth rereading.

The Methods section describes the extraction of "lipides" into a 1-phase system of organic solvents and subsequent conversion of the system to 2 phases. It is an elegant, simple modification of techniques then available for lipid extraction. Titration was done with a dilute solution of sodium hydroxide delivered from a microburet to change the color of the indicator, thymol blue, to green-yellow. Small amounts of lactic acid and acidic phospholipids were titratable contaminants in the extract but were found to be easily removed by additional aqueous washes (5). The method yielded a new and unexpected finding. Fatty acids were not a minor, insignificant spillover occurring with lipolysis, but surprisingly were as important a substrate for energy metabolism as glucose.

Vince tested the method on his own blood, before and after eating very fatty, and I would imagine delicious, breakfasts. He found that non-esterified fatty acid (NEFA) levels declined after the meal - a result verified by more orthodox studies on experimental subjects, reported in the JCI as follows: "In every case, after a mixed meal, NEFA fell sharply and remained below the fasting value for 2 or more hours; fat alone, when fed in sufficient quantity to produce gross lipemia, had no demonstrable effect on circulating NEFA. Feeding of glucose or injection of insulin caused a fall in concentration comparable to that occurring after the mixed meals, while the injection of epinephrine 


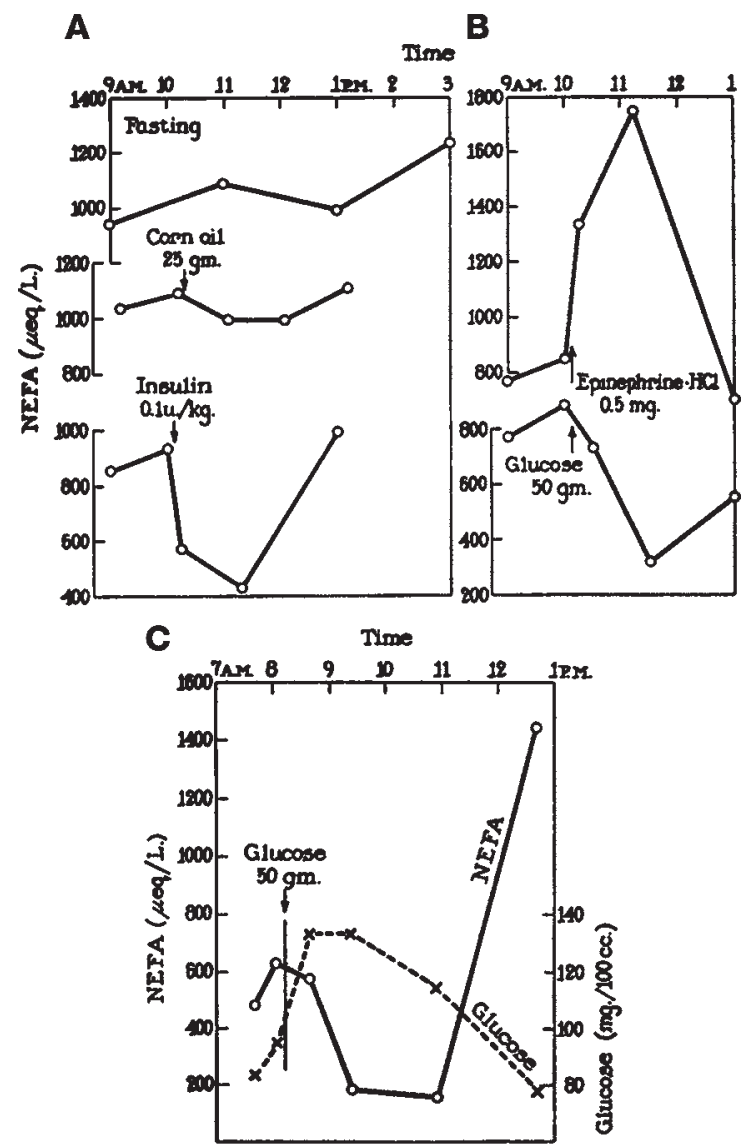

Figure 2

(A) Effects of fasting (average of eight experiments), corn oil (four experiments) and insulin (four experiments) on concentration of NEFAs. (B) Effects of epinephrine (three experiments) and glucose (14 experiments) on concentration of NEFAs in plasma. (C) Reciprocal variations of glucose and NEFAs in plasma after ingestion of glucose. Figure and legend adapted from ref. 3.

caused a marked rise" (Figure 2). He also noted that: "The responses of NEFA parallel the well-known effects of glucose, insulin, fasting and epinephrine on ketosis. Presumably both kinds of fatty acid - NEFA and ketone body - enter some metabolic process common to fat and carbohydrate." He cited Banting's 1922 article "Pancreatic extracts in the treatment of diabetes mellitus" (6) and other golden oldies, as well as more recent publications on lipemia, heparin, and clearing factor. Uncovering the relationship of NEFA to carbohydrate metabolism was truly innovative, and very soon the measurement and unraveling of the significance of plasma NEFA became a popular subject.

As with the spelling of lipids, a lively exchange developed over the correct acronym for free fatty acids. FFA was discouraged, since the acids were bound to albumin and not truly "free"; hence non-esterified or unesterified, NEFA or UFA, became the preferred names. The Journal of Lipid
Research, that important arbiter of good spelling, now permits FFA or NEFA but not UFA. Perhaps UFA sounds too much like the response to a blow to the abdomen, but whatever you call them, their study by Dole's method led to major advances. These included: (a) a focus on adipose tissue metabolism, as it became clear that this tissue was the major source of plasma NEFA, (b) examination of the role of fatty acids as modulators of the action of insulin, and (c) a clear demonstration of the importance of NEFA as an energy substrate for muscle, in particular cardiac muscle and "trained" skeletal muscles. The Gordon paper that accompanied Dole's work (4) pointed out the likelihood that NEFA is the main or even sole fuel for cardiac muscle, which led to (d) an appreciation of the role of catechol amines and peptide hormones in the control of lipolysis in adipose tissue and therefore the moment-tomoment availability of energy.
As might be expected, some publications featuring the new method did not greatly expand the horizons of our understanding. NEFAs were measured in humans and animals in the old and the young, the anxious and the calm, during sleep or exercise, etc. - data that constituted many a thesis for graduate degrees. Such endeavors keep papers flowing through our journals - but every so often we come upon a gem like the Dole article of 1956. Now his technique has been replaced by automated, enzymatic methods, but the many derivatives of his work continue to enrich our understanding of metabolism.

I wonder about his cryptic comment: "One thing leads to another." Dole was skilled in the tools of laboratory research and had great interest in human metabolism. His ideas were often very imaginative and not fettered by what everyone else was doing. He spent more time reflecting than reading the literature of the day. Perhaps more intensive reading of the literature might have dampened his willingness to pursue this line of work. Can you imagine what a peer review group might have done with a request for funds to support such an effort? The method would have been criticized as being too crude to produce useful data, since it did not involve the removal of interfering acidic materials from the lipid extract. Furthermore, the mixture of fatty acids contained many different fatty acids with variations in chain length and saturation. With such a motley mix, how could one expect to obtain useful data on specific biochemical pathways to enlighten our understanding of metabolism in a reliable way? As the fatty acids in plasma were then considered an inconsequential spillover from lipolysis, such research would be considered a classic example of a fishing expedition.

Vince marched to a different drummer, moving along from one thing to another. Awaiting other techniques to analyze each component of the fatty acid mixture with great accuracy would miss the point. Insisting that studies be done first in mice, rats, worms, yeast, or tissue culture would have sidetracked his march, but studying small numbers of people (particularly one's self) was just right. Animals would probably respond to experimental measures with such panic as to have erratic and very high NEFA levels. Using samples from humans first was not only wise but probably essential. The physician-scientist armed with a good tool can catch some big ones on such fishing 
expeditions. Sometimes the best we can do for imaginative investigators is to leave them alone so that one thing can lead to another. Making it possible for physician-scientists to examine the mysteries of human physiology and disease in their own style may lead them into blind alleys, but sometimes to breathtaking new vistas. I believe this is as true now as it was in 1956, and I thank Vince Dole and the JCI for reminding me.
Address correspondence to: Jules Hirsch, Laboratory of Human Behavior \& Metabolism, Rockefeller University, 1230 York Avenue, New York, New York 10021, USA. Phone: (212) 327-8426; Fax: (212) 3277150; E-mail: hirsch@mail.rockefeller.edu.

1. Fruton, J.S., and Simmonds, S. 1953. General Biochemistry. John Wiley \& Sons, Inc. New York, New York, USA/London, United Kingdom. 940 pp.

2. Fredrickson, D., and Gordon, R.S., Jr. 1958. Transport of fatty acids. Physiol. Rev. 38:585-630.
3. Dole, V.P. 1956. A relation between non-esterified fatty acids in plasma and the metabolism of glucose. J. Clin. Invest. 35:150-154.

4. Gordon, R.S., and Cherkes, A. 1956. Unesterified fatty acid in human blood plasma. J. Clin. Invest. 35:206-212.

5. Trout, D.L., Estes, E.H., Jr., and Friedberg, S.J. 1960. Titration of free fatty acids of plasma: a study of current methods and a new modification. J. Lipid Res. 1:199-202.

6. Banting, F.G., Best, C.H., Collip, J.B., Campbell, W.R., and Fletcher, A.A. 1922. Pancreatic extracts in the treatment of diabetes mellitus. Can. Med. Assoc. J. 12:141-146.

\title{
The birth of clinical body plethysmography: it was a good week
}

\author{
John B. West \\ Department of Medicine, University of California, San Diego, La Jolla, California, USA.
}

\begin{abstract}
Nearly fifty years ago, Arthur B. DuBois, Julius H. Comroe Jr., and their colleagues published two papers on the use of body plethysmography to measure lung volume and airway resistance. These two articles in the JCI are almost the most-cited doublet in the Journal's entire archive. Remarkably, the methods described then are still in use today in clinical pulmonary function laboratories. Though body plethysmography had been used before, there were serious technical problems; it was extraordinary that DuBois managed to solve most of these in one week. Times have changed and molecular medicine now dominates the JCI, but these articles remind us that biomedical research goes beyond the molecular.
\end{abstract}

Congratulations to the JCI on the occasion of its 80 th birthday. Happily the editors have used the occasion to highlight two papers by Arthur B. DuBois, Julius H. Comroe Jr., and their colleagues on the use of the body plethysmograph. Together, these two papers hold the record as the fourth most-cited articles $(3,109$ times as of this writing) in the entire archive of the JCI $(1,2)$. Therefore, congratulations are also in order for Arthur DuBois, who continues to be productive nearly 50 years after these publications appeared and who celebrated his own 80th birthday last year. Julius Comroe Jr. died in 1984.

These two classic articles describe how the body plethysmograph can be used for measuring thoracic gas volume on the one hand and lung airway resistance on the other. The word "plethysmograph" derives from the Greek plethusmos mean-

Conflict of interest: The author has declared that no conflict of interest exists.

Citation for this article: J. Clin. Invest. 114:1043-1045 (2004). doi:10.1172/JCI200422992. ing "increase" and graphe meaning "writing" and usually refers to a device for determining changes in the volume of an organ or limb. The body plethysmograph measures changes in volume of the whole body and is essentially a rigid box in which the patient sits while the small changes of pressure in the box can be measured as he or she makes respiratory maneuvers (Figures 1 and 2). The basic principle is Boyle's law, that is, that the pressure and volume of a gas are inversely related at constant temperature.

Briefly, to measure lung volume, the patient makes an inspiratory effort against a closed airway and the resulting slight increase in volume of the lung reduces the free volume of air in the box, thereby increasing its pressure. At the same time, the increase in volume of the lung results in a reduction of pressure in

\section{Figure 1}

Arthur DuBois with the body plethysmograph that was used for the two classic papers discussed here. Reproduced with permission from the Journal of Applied Physiology (7). the airway; from the changes in the two pressures and the volume of the box, the volume of the lung can be derived. The calculation is simplified by displaying the two pressures on the $x$ and $y$ axes of an oscilloscope. In the modern pulmonary function laboratory, this is a much easier way of measuring lung volume than gas dilution techniques using, for example, helium equilibration or nitrogen washout. A diagram of the apparatus is shown in Figure 3 (1).

In the first article, the authors showed that the plethysmographic technique gave values for lung volume that were essentially the same as those obtained by

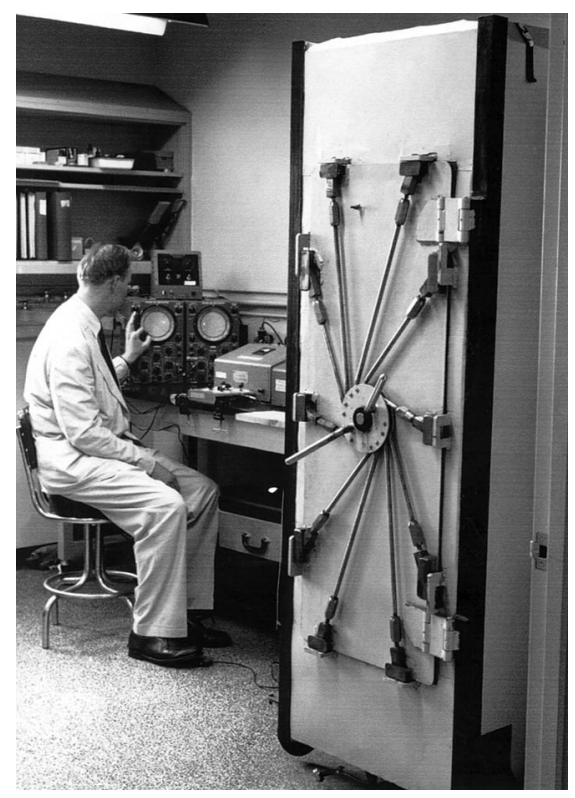

